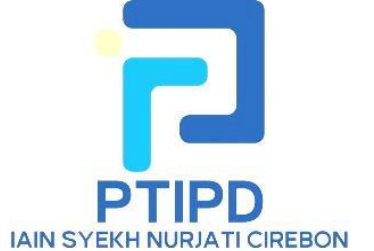

ITEJ Desember-2019, Volume 4 Nomor 2 Page 99 - 113

\section{ITEJ}

Information Technology Engineering Journals eISSN : 2548-2157

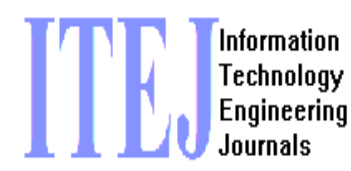

Url : https://syekhnurjati.ac.id/journal/index.php/itej

Email : itej@syekhnurjati.ac.id

\title{
A Survey on Machine learning and IoT
}

\author{
Inkreswari Retno Hardini \\ School of Electrical Engineering and Informatics, \\ Institut Teknologi Bandung \\ Bandung, Indonesia \\ inkreswari@gmail.com
}

\begin{abstract}
Internet of Things is an intelligence devices that can connect to any other devices. Based on that ability to connect and its intelligence, it makes people to create an intelligence device and capable to learn like human brain. To accomplish that goal, machine learning is the solution. Combination between machine learning and IoT generate a revolution in human life and application industry. The combination also generate new trend in market. Therefore, in this paper will be discuss about machine learning including machine learning technique and algorithm and also discuss about IoT including architecture and elements. Then in this paper will discuss about some researches that have already done that combine IoT with machine learning approach, including issue and challenge in those researches.
\end{abstract}

Keywords-Internet of Things, Machine learning, IoT components, IoT architecture, Machine learning algorithm, Machine learning technique.

\section{PENDAHULUAN}

Dewasa ini perkembangan teknologi semakin pesat. Selain itu, teknologi internet juga semakin berkembang, seperti jaringan 5G[1], cloud computing dan jaringan virtual. Dampak dari itu semua yaitu munculnya perangkat-perangkat canggih seperti smart phone, perangkat smart home dan perangkat lainnya yang dapat dengan mudahnya terkoneksi ke internet. Semakin banyaknya perangkat yang terkoneksi ke internet.menyebabkan lalu lintas data tumbuh pesat. Hal tersebut terjadi karena perangkat-perangkat tersebut melakukan transaksi data di internet.

Melihat fenomena dimana munculnya perangkat-perangkat yang canggih dan perkembangan perangkat teknologi serta hubungannya dengan internet, membuat munculnya bidang ilmu Internet of Things (IoT). IoT sendiri sangat identik dengan revolusi industri 4.0 yang menitikberatkan proses otomasi, pengolahan data dalam jumlah besar (Big Data analytics), kecerdasan buatan (Artificial Intelligence) dan Internet of Things. Selain itu, dari jumlah perangkat yang serba terkoneksi dengan internet, maka keseluruhan aktivitas sekarang ini pasti melibatkan pertukaran data atau transaksi data lewat internet. Melihat dari banyaknya data yang tersedia dan dapat diolah menjadi sebuah informasi atau pengetahuan yang berguna, serta berangkat dari kebutuhan manusia akan informasi yang dapat 
diperoleh melalui teknologi yang saat ini berkembang dan yang mereka miliki, membuat bidang ilmu machine learning menjadi penting.

Machine learning berangkat dari pemikiran bagaimana agar teknologi yang ada dapat membantu manusia dalam memenuhi kebutuhan dan pekerjaannya. Hal tersebut dilakukan dengan melibatkan data-data yang tersedia di internet atau data yang didapatkan dari perangkat-perangkat pengumpul data (sensor) yang kemudian data tersebut diproses sehingga teknologi yang ada dapat memberikan pengetahuan yang merupakan hasil olahan dari data yang tersedia. Pengetahuan tersebut kemudian dapat memenuhi kebutuhan si pengguna.

IoT membuat perangkat dapat melihat, mendengar, berfikir dan melakukan sebuah pekerjaan. IoT mengubah perangkat-perangkat menjadi perangkat yang cerdas dengan mengeksploitasi komputasi perangkat, teknologi komunikasi, jaringan sensor, protocol internet dan aplikasinya. IoT memungkinkan perangkat nantinya dapat membantu dalam hal pengambilan keputusan, dimana pengambilan keputusan erat kaitannya dengan machine learning [2][3]. Machine learning dalam IoT saling berkaitan dan berperan penting. Banyak penelitian yang menggabungkan machine learning dengan IoT. Machine learning digunakan untuk mengolah data yang dikumpulkan oleh perangkat IoT sesuai dengan tujuan atau keperluan spesifik. Diharapkan kedepannya IoT akan semakin memudahkan aktivitas dan memudahkan dalam memperoleh pengetahuan atau infomasi yang menjangkau semua bidang kehidupan, baik kesehatan, home appliances, pendidikan, lingkungan dan lain sebagainya.

IoT dan smart city tidak bisa dipisahkan. Banyak penelitian yang melibatkan IoT utuk menunjang keberlangsungan smart city. Smart city menggunakan teknologi untuk menjalani aktivitas sehari-hari. Untuk merealisasikan konsep tersebut, IoT dan perpaduannya dengan machine learning merupakan salah satu contoh perpaduan yang cocok. Seperti penelitian yang dilakukan oleh Farhad [4] yang mengimplementasikan machine learning dan IoT untuk domain healthcare. Selain itu terdapat penelitian yang dilakukan oleh Alhajri., dkk [5] yang menggunakan pendekatan machine learning untuk implementasi aplikasi IoT dalam smart home. Penerapan IoT dan machine learning dalam smart city dilakukan dalam penelitian Bakhsi [6] yang menggunakan Analisa machine learning untuk diterapkan pada aplikasi IoT untuk mengatur pembuangan pada suatu kota yang menerapkan konsep smart city.

Pada paper ini akan mencoba mengangkat mengenai survey di bidang IoT dan machine learning. Kemudian dilanjutkan dengan pemaparan mengenai penelitian di bidang IoT yang melibatkan machine learning. Lalu mengangkat isu dan tantangan yang mungkin dihadapi dan bisa diangkat sebagai bahan penelitian selanjutnya. Skema paper dijelaskan sebagai berikut: Bagian II menjelaskan tentang survey IoT, Bagian III menjelaskan tentang survey machine learning, Bagian IV menjelaskan tentang penelitian di bidang machine learning dan IoT, Bagian V menjelaskan tentang tantangan dan isu mengenai machine learning dan IoT, Bagian VI menjelaskan tentang penelitian kedepan yang mungkin dilakukan.

\section{INTERNET OF THINGS}




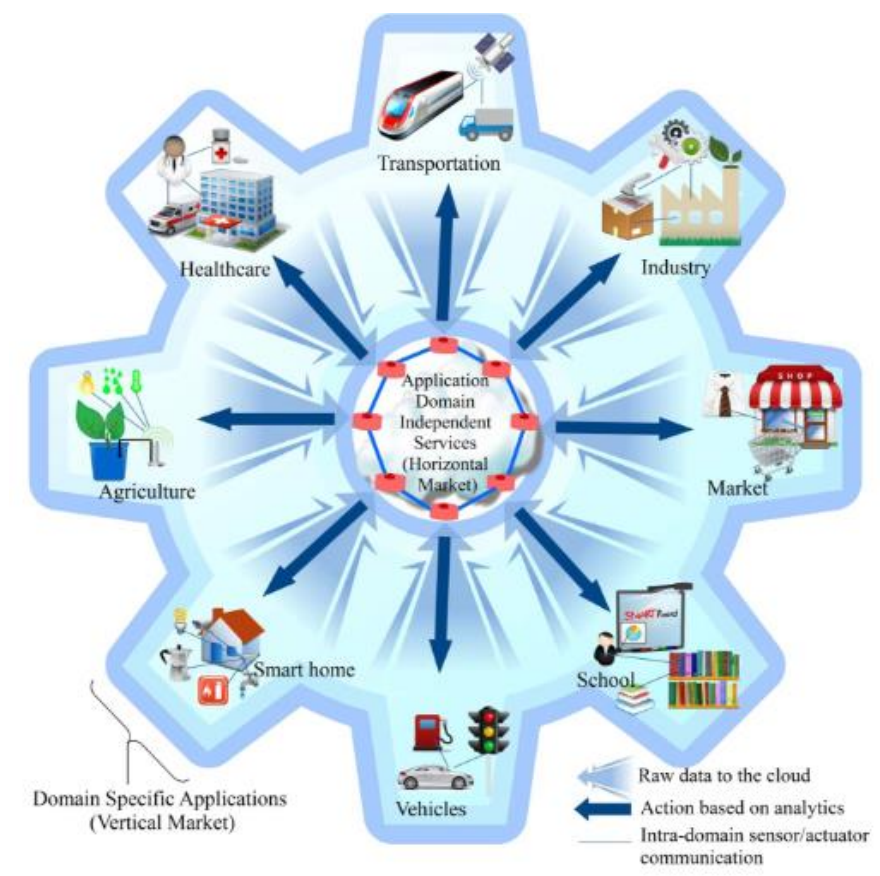

Gambar 1 Domain vertical dan horizontal IoT [2]

\section{A. Pendahuluan}

Tingkat pertumbuhan perangkat yang terhubung ke internet semakin pesat. Hal tersebut melahirkan kesadaran dan bidang ilmu baru yaitu Internet of Things. Internet of Things (IoT) membuat perangkat dapat melihat, mendengar, berpikir, mengolah informasi serta membantu dalam pengambilan keputusan. Hal tersebut dapat dilakuakn dengan melakukan komputasi perangkat, mengeksploitasi sensor, protokol komunikasi dan aplikasi IoT [2][3]. Banyak domain yang dapat dijadikan pengaplikasian IoT dan diharapkan dengan penerapan IoT di bidang tersebut, kualitas hidup menjadi meningkat. Domain tersebut antara lain kesehatan, lingkungan, transportasi, otomasi industri, tanggap darurat terhadap bencana alam, pertanian, pendidikan dan pengambilan keputusan. Objekobjek dalam domain pengaplikasian yang disebutkan dalam penelitian Al-Fuqaha., et al. [2] disebut juga sebagai domain vertikal. Objek-objek tersebut menjalankan tugas sebagaimana mestinya. Sementara untuk komputasi perangkat IoT dan layanan analisis untuk IoT masuk ke dalam application domain independent service (domain horizontal). Kedua domain ini saling berhubungan, dimana tiap domain vertikal akan berhubungan langsung dengan domain horizontal. Sensor dan aktuator di tiap domain berkomunikasi secara langsung satu sama lain. Hal tersebut dapat dilihat pada Gambar 1.

\section{B. Arsitektur Internet of Things}

Internet of Things (IoT) harus mampu menghubungkan ribuan, jutaan bahkan milyaran perangkat lewat internet. Hal tersebut membuat pentingnya terdapat layer arsitektur yang fleksibel. Mengacu pada penelitian yang sudah dikerjakan oleh peneliti-peneliti sebelumnya, ada beberapa model arksitektur IoT. Model pertama adalah model 3 layer atau dikenal dengan model dasar. Model ini terdiri dari layer perception, layer network dan layer application seperti dapat dilihat pada Gambar 2. Model ini digunakan di dalam penelitian $\mathrm{Wu}$., et al.[7] yang melakukan penelitian mengenai arsitektur IoT, lalu dalam penelitian Yang., et al[8] yang meneliti tentang arsitektur IoT dan teknologi IoT, dan dalam penelitian Khan., et al[3] yang membahas tentang arsitektur IoT, aplikasi dan tantangan IoT. 


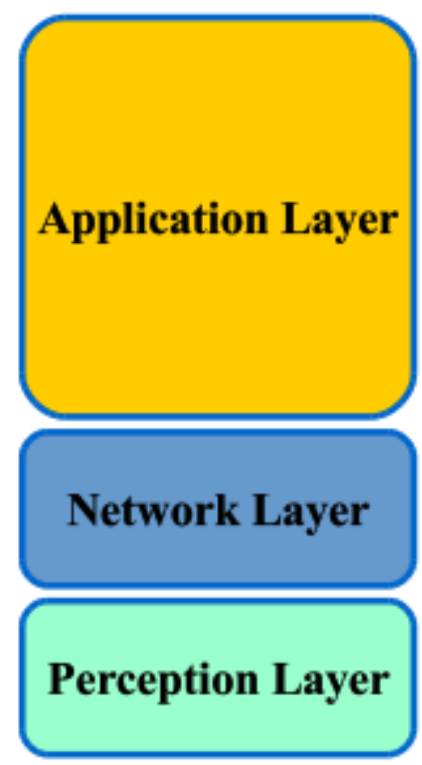

Gambar 2 Model arsitektur IoT 3 layer [3], [7], [8]

Penelitian selanjutnya ada yang menggunakan model IoT 5 layer. Kelima layer tersebut diusulkan dalam penelitian Atzori., et al.[9] dan Chaqfeh., et al[10] yang membahas tentang middleware sebagai solusi untuk IoT. Kelima layer tersebut dapat dilihat pada

\begin{tabular}{|c|c|c|c|}
\hline \multicolumn{2}{|c|}{ Application Layer } & Applications & Business Layer \\
\hline \multicolumn{2}{|c|}{ Middleware Layer } & $\begin{array}{c}\text { Service } \\
\text { Composition }\end{array}$ & $\begin{array}{c}\text { Application } \\
\text { Layer }\end{array}$ \\
\hline \multicolumn{2}{|c|}{ Coordination Layer } & $\begin{array}{c}\text { Service } \\
\text { Management }\end{array}$ & $\begin{array}{c}\text { Service } \\
\text { Management }\end{array}$ \\
\hline \multicolumn{2}{|c|}{$\begin{array}{c}\text { Backbone } \\
\text { Network Layer }\end{array}$} & Object Abstraction & Object Abstraction \\
\hline \multirow{2}{*}{$\begin{array}{l}\text { Existed alone } \\
\text { Application } \\
\text { System }\end{array}$} & $\begin{array}{l}\text { Access } \\
\text { Layer }\end{array}$ & \multirow[b]{2}{*}{ Objects } & \multirow[b]{2}{*}{ Objects } \\
\hline & \begin{tabular}{|c|} 
Edge \\
eechnology
\end{tabular} & & \\
\hline
\end{tabular}

Gambar 3.

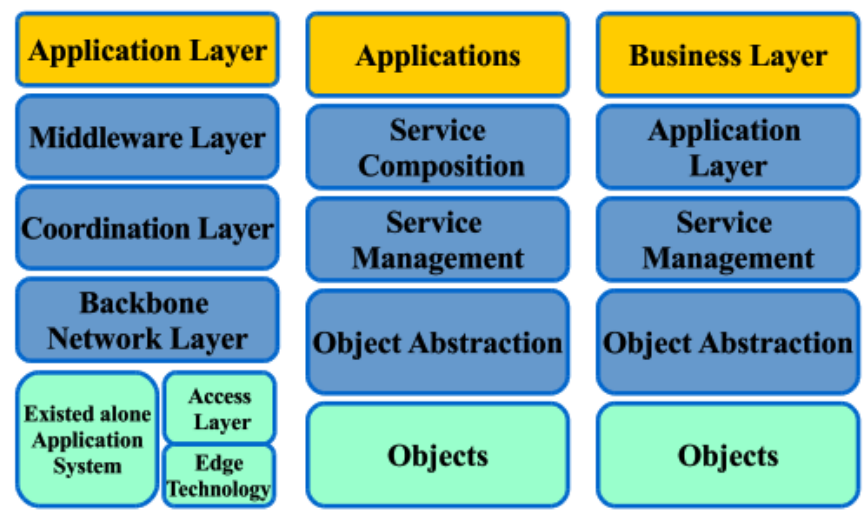

Gambar 3 Model arsitektur IoT 5 layer [2], [9], [10] 


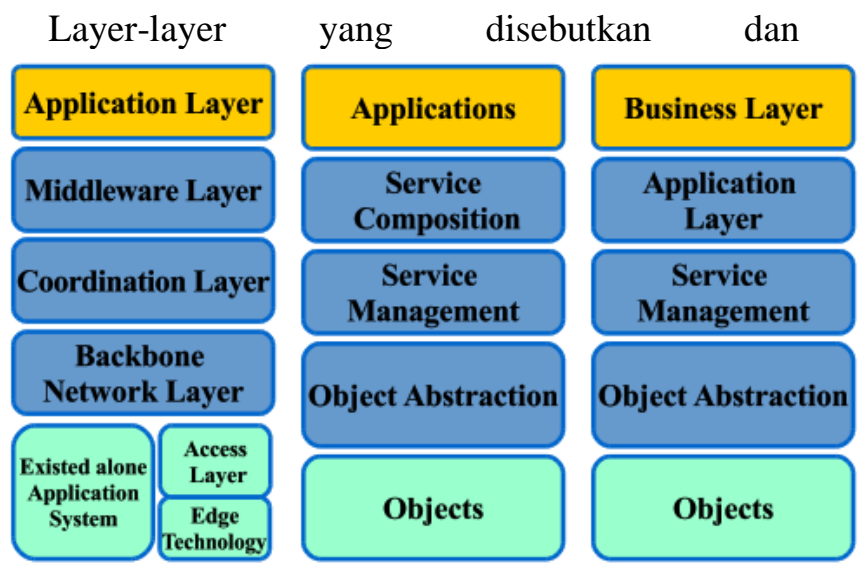

Gambar 3, masing-masing akan dijelaskan sebagai berikut.

1) Object Layer: Layer pertama dalam arsitektur IoT. Biasa juga disebut dengan perceprion layer. Layer ini mewakili perangkat fisik dalam IoT berupa sensor yang digunakan untuk mengumpulkan data dari lingkungan eksternal dan untuk memproses informasi. Layer ini terdiri dari sensor dan actuator untuk menjalankan fungsi yang berbeda-beda. Contohnya antara lain fungsi untuk lokasi, suhu, berat, gerak, getaran, kecepatan, kelembapan dsb [2], [9]. Layer ini mendigitalisasi data dan mentransfer data menuju ke layer object abstraction melalui saluran yang aman. Big data tercipta dalam lingkup IoT merupakan hasil dari layer object ini [3], [7], [9].

2) Object Abstraction layer: Layer ini bertugas sebagai perantara untuk mengirimkan data hasil dari layer object menuju ke layer service management melalui saluran yang aman. Saluran yang dimaksud antara lain teknologi RFID, 3G, GSM, UMTS, WiFi, Bluetooth Low Energy, Infrared, ZigBee, dsb [2], [3], [9], [10].

3) Service Management Layer: Layer ini disebut juga layer middleware. Layer ini menghubungkan layanan dengan si pemohon layanan (requester) dengan mencocokkan berdasarkan alamat dan nama. Pada layer ini dilakukan pemrosesan terhadap data yang diterima oleh layer object (sensor). Pemrosesan data yang dilakukan digunakan agar dapat melakukan proses pengambilan keputusan. Selain menerima data kemudian memprosesnya dan menghasilkan proses pengambilan keputusan, layer ini juga digunakan untuk menyampaikan layanan sesuai dengan yang dibutuhkan oleh user melalui protocol jaringan [2], [3], [10].

4) Application Layer: Layer ini merupakan layer yang dilihat oleh pengguna atau pihak yang membutuhkan informasi. Layer ini menyajikan layanan sesuai dengan yang dibutuhkan oleh pengguna. Sebagai contoh, jika pengguna membutuhkan informasi terkait kelembaban udara di suatu ruangan, maka layer inilah yang akan menampilkan informasi atau pengetahuan mengenai kelembaban ruangan tersebut [2], [9]. Layer ini penting dan sangat menentukan kualitas dari perangkat IoT, karena layer ini yang merupakan produk layanan cerdas yang diharapkan dapat memenuhi kebutuhan pengguna [7], [8]. Layer ini mencakup berbagai domain vertical seperti kesehatan, lingkungan, trasportasi dsb [2], [4]-[6], [11].

5) Business Layer: Layer ini berfungsi untuk membangun model bisnis, flowchart berdasarkan data yang dihasilkan di layer application. Layer ini juga berfungsi untuk mendesain, menganalisis, mengimplementasikan, mengevaluasi, mengontrol dan mengembangkan sistem IoT. Pada kesimpulannya layer ini merupakan monitoring terhadap 4 layer lainnya [2][9].

Penelitian yang menggunakan 3 layer seringkali tidak sesaui lingkungan nyata. Sementara pada 5 layer, pada layer application digunakan sebagai antar muka untuk interaksi antara pengguna (end user) dengan perangkat IoT untuk mendapatkan informasi. Layer application ini juga digunakan sebagai antar muka bagi layer bisnis, dimana analisis tingkat tinggi dan laporan dapat diperoleh atau ditampilkan kepada pengguna pada layer application ini [2].

\section{Elemen Internet of Things}

Memahami apa saja elemen yang terdapat pada perangkat IoT membantu kita untuk lebih memahami cara kerja dan fungsionalitas dari IoT. Berdasarkan penelitian yang dilakukan oleh AlFuqaha., et.al [2] mengenai survey teknologi IoT, terdapat 6 elemen dari IoT. Elemen tersebut dapat 
dilihat pada Gambar 4. Pada Tabel 1 juga dipaparkan mengenai contoh dari elemen IoT. Berikut akan dijelaskan masing-masing dari elemen sehingga pemahaman mengenai bagaimana cara kerja dan fungsionalitas dari IoT semakin meningkat.

Tabel 1 Elemen IoT dan Contoh

\begin{tabular}{|l|l|l|}
\hline \multicolumn{2}{|c|}{ Elemen IoT } & \multicolumn{2}{c|}{ Contoh } \\
\hline Identification & Penamaan & EPC, uCode \\
\cline { 2 - 3 } & Pengalamatan & IPv4, IPv6 \\
\hline Sensing & $\begin{array}{l}\text { Smart sensor, Wearable sensing device, Embedded sensor, } \\
\text { actuator, tag RFID }\end{array}$ \\
\hline Communication & $\begin{array}{l}\text { RFID, NFC, Bluetooth, IEEE 802.15.4, WiFi, Z-wave dan LTE- } \\
\text { Advanced }\end{array}$ \\
\hline Computation & Hardware & Arduino, Raspberry Pi, BeagleBone, Smartphone \\
\cline { 2 - 3 } & Software & OS (TinyOS, Android, LiteOS, dsb), Cloud (Hadoop, dsb) \\
\hline Service & $\begin{array}{l}\text { Identitiy-related (contoh: Shipping), Collaborative-aware (contoh: } \\
\text { smart home), Ubiquitous (contoh: smart city), Information } \\
\text { aggregation (contoh: smart grid) }\end{array}$ \\
\hline Semantic & RDF, OWL \\
\hline
\end{tabular}

1) Identification: Elemen ini penting dalam IoT karena berfungsi sebagai pengenal perangkat IoT. Perangkat IoT yang terhubung di internet jika ingin dilakukan pengolahan terhadap perangkat tersebut dan data dari perangkat tersebut diambil, maka agar tidak keliru dengan perangkat lainnya dan perangkat dapat dikenali maka elemen inilah yang berperan. Metode identification yang digunakan dalam IoT antara lain electronic product codes (EPC) dan ubiquitous code (uCode) [2][12]. Dalam IoT, penting untuk membedakan antara ID objek dan alamat objek. ID objek memiliki arti nama dari objek tersebut misalnya "nama objek 1". Sedangkan alamat memiliki arti alamat dimana objek tersebut berada dalam jaringan komunikasi dimana perangkat IoT itu digunakan. Metode pengalamatan dalam IoT menggunakan IPv4 dan IPv6. Membedakan antara ID objek dan alamat objek dalam elemen identification IoT sangat penting adanya. Hal tersebut karena metode untuk identifikasi objek dalam IoT berisfat umum, tidak unik sehingga dengan dibantu dengan pengalamatan objek, objek IoT dapat dibedakan antara satu dengan yang lainnya dengan kata lain alamat objek berguna sebagai pembeda [2]. Kesimpulannya metode identifikasi digunakan untuk menyediakan identifikasi yang jelas kepada tiap objek dalam jaringan dimana IoT digunakan.

2) Sensing: Elemen sensing dalam IoT berfungsi untuk mengumpulkan data melalui objek-objek perangkat IoT yang digunakan. Teknologi sensing yang digunakan dalam IoT antara lain smart sensor, actuator atau perangkat wearable sensing [1],[8]. Perangkat wearable sensing disini maksudnya adalah perangkat yang dapat dikenakan oleh manusia seperti gelang kesehatan. Data yang dikumpulkan oleh objek perangkat IoT seperti yang telah disebutkan tadi, dikumpulkan 
untuk kemudian dikirim ke database atau cloud.

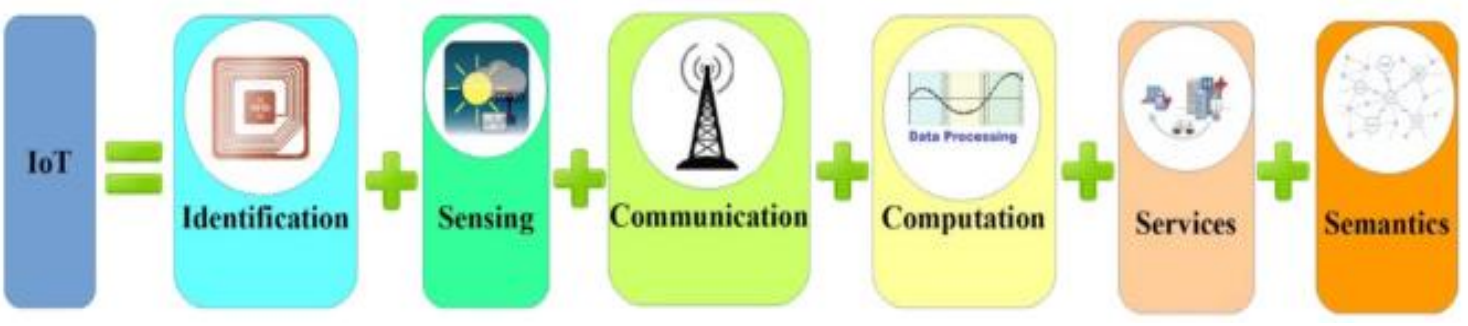

Gambar 4 Elemen IoT[2]

Data yang sudah terkumpul di cloud atau database nantinya akan diolah sesuai dengan tujuan spesifik untuk mendapatkan informasi pengetahuan sesuai dengan tujuan awal untuk apa data tersebut dikumpulkan. Teknologi lainnya yang dapat berperan sebagai sensing adalah tag RFID. Kesimpulannya elemen sensing dalam IoT berperan untuk media pengumpulan data, dimana sensing itu dapat berupa smart sensor, tag RFID, actuator atau perangkat sensor yang dapat dikenakan oleh manusia (wearable sensing device).

3) Communication: Elemen communication dalam IoT berfungsi menghubungkan berbagai perangkat IoT untuk dapat saling berhubungan sehingga data yang dibawa oleh masing-masing perangkat dapat diolah dan menghasilkan informasi pengetahuan yang sesuai dengan layanan yang dibutuhkan pengguna (end user). Protokol komunikasi yang digunakan dalam IoT antara lain WiFi, Bluetooth, IEEE 802.15.4, Z-wave dan LTE-Advanced. Selain protocol komunikasi, dalam elemen communication IoT terdapat teknologi spesifik yang dapat digunakan oleh perangkat-perangkat IoT agar dapat saling berkomunikasi, yaitu teknologi RFID dan NFC [2]. RFID merupakan singkatan dari Radio Frequency Identification. RFID terdiri dari 2 bagian yaitu tag dan reader. Tag RFID berbentuk chip atau label yang melekat pada objek perangkat. Tag RFID berfungsi sebagai identitas objek perangkat. Reader RFID mentransmisikan sinyal query kepada tag, kemudian reader akan menerima pantulan sinyal tadi dan kemudian reader akan meneruskannya ke database. Tag RFID dapat berupa RFID aktif, pasif dan semi-pasif/ semi-aktif. Tag aktif menggunakan baterai, sementara tag pasif tidak menggunakan baterai. Untuk tag semi-aktif/semi-pasif menggunakan papan power (board power) [13].

NFC merupakan singkatan dari Near Field Communication. Teknologi NFC dapat bekerja untuk komunikasi dengan range jarak sampai $10 \mathrm{~cm}$ antara reader dengan tag pasif [14]. Teknologi WiFi menggunakan gelombang radio untuk bertukar data antar objek dengan jarak antar objek sebesar 100 m. Teknologi WiFi memungkinkan perangkat untuk saling berkomunikasi dan bertukar informasi tanpa menggunakan router [15]. Teknologi komunikasi selanjutnya adalah Bluetooth. Bluetooth merupakan teknologi komunikasi yang digunakan untuk bertukar data antar perangkat dengan jarak yang dekat menggunakan short-wavelength radio [16]. LTE merupakan singkatan dari Long-Term Evolution yang merupakan standar untuk komunikasi tanpa kabel (wireless) untuk transfer data berkecepatan tinggi. Transfer data yang terjadi pada teknologi LTE adalah transfer data antar mobile phone berdasarkan teknologi GSM/UMTS [17].

4) Computation: Elemen ini berfungsi sebagai unit pemrosesan. Elemen ini berfungsi sebagai otak dari IoT. Elemen ini bertugas mengolah data yang sudah terkumpul di database. Data akan diolah agar menghasilkan informasi yang sesuai dengan layanan yang diminta oleh pengguna. Elemen komputasi dalam IoT berupa sistem operasi antara lain TinyOS, Android, LiteOS [2]. Selain system operasi, teknologi komputasi yang digunakan dalam IoT yaitu cloud. Cloud memegang peranan penting dalam komputasi IoT, karena cloud menyediakan fasilitas bagi objek IoT untuk mengirimkan data yang dikumpulkan ke cloud. Cloud juga berfungsi menyediakan fasilitas untuk big data agar dapat diproses secara real time.

5) Service: Berdasarkan penelirian yang dilakukan oleh Gigli dan Koo [18], layanan (service) yang terdapat pada IoT dikategorikan menjadi 4 kelas, antara lain: identity-related services, information aggregation services, collaborative aware, ubiquitous. Disini contoh dari penerapan layanan identity-related services adalah shipping, lalu contoh dari layanan information aggregation services adalah smart grid, selanjutnya smart home adalah contoh layanan dari collaborative aware, dan smart city merupakan contoh layanan dari Ubiquitous. Identity-related services merupakan layanan dasar dan merupakan layanan yang paling penting dan digunakan dalam jenis layanan 
lainnya, bukan hanya di IoT. Layanan identity-related services berfungsi bagi aplikasi yang berhubungan dengan objek di dunia virtual, untuk mengidentifikasi atau sebagai pengenal objek tersebut. Selanjutnya layanan information aggregation berguna untuk mengumpulkan data kasar hasil perolehan sensor, dimana data kasar ini perlu untuk diolah kembali agar dapat disampaikan dalam bentuk aplikasi IoT yang berisi layanan yang spesifik. Sementara itu layanan collaborative-aware berfungsi sebagai layanan yang menggunakan data yang diperoleh dan telah disimpan sebagai bahan untuk proses pengambilan keputusan. Untuk layanan ubiquitous, digunakan untuk menyediakan layanan collaborative-aware kapanpun dibutuhkan untuk siapapun dan dimanapun [2][18].

Sejatinya tujuan dari aplikasi IoT yang dibangun adalah untuk mencapai level layanan ubiquitous. Akan tetapi untuk mencapai level ini tidak mudah dan banyak tantangannya. Kebanyakan dari aplikasi IoT yang sudah ada adalah aplikasi yang menyediakan layanan identity-related, information aggregation dan collaborative-aware. Contoh aplikasi IoT yang sudah ada yaitu smart healthcare dan smart grid masuk dalam kateogri layanan information aggregation, sementara aplikasi IoT seperti smart home, smart building, dan otomasi industri masuk kepada layanan collaborative-aware [2].

6) Semantic: Layanan ini memiliki kemampuan untuk mengekstrak pengetahuan untuk menyediakan layanan yang dibutuhkan. Ektraksi pengetahuan yang terjadi di layanan ini termasuk menggunakan sumber daya dan infromasi modeling. Layanan ini juga termasuk menganalisa data yang digunakan untuk membuat keputusanyang tepat agar dapat memberikan layanan yang tepat dan sesuai dengan yang dibutuhkan. Oleh karena itu, dengan kata lain semantic adalah otak dari IoT karena dapat mengelompokkan kebutuhan sesuai dengan sumber daya yang tepat [2][9]. Kemampuan layanan semantic ini didukung oleh teknologi web semantic antara lain Resource Description Framework (RDF) dan Web Ontology Language (OWL).

\section{MACHINE LEARNING}

\section{A. Pendahuluan}

Banyaknya perangkat yang terhubung ke internet menyebabkan banyaknya transaksi data yang terjadi di internet. Kemudahan teknologi untuk saling terhubung saat ini menyebabkan volume data meningkat. Perkembangan teknologi, meningkatnya volume data membuat kebutuhan informasi pengguna semakin beragam. Dengan banyaknya data lalu beragamnya kebutuhan pengguna akan sebuah informasi atau pengetahuan serta kemampuan teknologi perangkat saat ini yang semakin canggih, memunculkan sebuah paradigma bagaimana agar teknologi yang ada dapat membantu pengguna dalam mendapatkan informasi atau memudahkan pengguna. Sehingga keberadaan machine learning sangat penting untuk mewujudkan itu semua. Machine learning memampukan sebuah perangkat untuk bisa membantu pekerjaan pengguna atau menghasilkan informasi seperti yang diinginkan pengguna dengan cara perangkat tersebut dilatih dengan menggunakan data-data yang ada [11]. Sejalan dengan penelitian yang dilakukan oleh Jaspers, machine learning adalah sebuah proses yang secara otomatis berkembang atau belajar dari pengalaman atau riset, dan kemudian bertindak tanpa di program terlebih dahulu (karena sudah dilatih menggunakan data riset atau data terdahulu) [19].

Komputasi dengan menggunakan machine learning menjadi lebih efektif dan efisien. Machine learning mampu mengolah data bahkan yang kompleks sekalipun dengan lebih cepat dan akurat. Kelebihan dari machine learning adalah terletak pada kemampuannya untuk menyediakan solusi umum melalui arsitekturnya yang dapat mengalami proses pembelajaran untuk meningkatkan kinerja [19], [20]. Machine learning menggunakan data terdahulu untuk mengolah data saat ini. Semakin hari algoritma machine learning semakin berkembang. Sampai saat ini machine learning mampu digunakan untuk menyelesaikan berbagai jenis permasalahan. Karena kemampuannya untuk menyelesaikan berbagai macam masalah, maka machine learning dapat diterapkan pada berbagai bidang aplikasi kehidupan untuk membantu dalam hal prediksi dan membantu proses pengambilan keputusan [19].

\section{B. Algoritma Machine learning}

Algoritma dalam machine learning berfungsi untuk membantu perangkat atau sistem untuk melakukan proses prediksi dan proses pengambilan keputusan dengan cara mempelajari data-data sebelumnya agar bisa mengeksekusi data saat ini. Algoritma dalam machine learning membantu 
sistem menemukan pola untuk berpikir. Ada beberapa algoritma machine learning yang sering digunakan. Algoritma tersebut umumnya dikategorikan berdasarkan teknik machine learning. Teknik machine learning akan dibahas pada bagian berikutnya. Berikut akan dijelaskan beberapa algoritma machine learning sehingga dapat membantu untuk memahami implementasi dari algoritma dan membantu pengguna untuk memilih algoritma yang sesuai dengan masalah yang sedang dihadapi.

1) Regression: Algoritma regresi merupakan algoritma supervised learning. Algoritma ini akan menghasilkan keluaran berupa prediksi berdasarkan masukan input. Variabel dari algoritma regresi dapat berupa variable kontinyu dan variable kuantitatif. Algoritma ini merupakan algoritma prediksi yang umum digunakan karena sederhana dan menghasilkan hasil prediksi yang akurat. Rumus dari algoritam regresi adalah sebagai berikut seperti terlihat di persamaan 1 [19], [20].

$$
Y=f(x)+\varepsilon
$$

Dimana Y merupakan variable dependent (output), lalu $\mathrm{X}$ merupakan variable independent, $\mathrm{f}$ merupakan fungsi relasi antara $\mathrm{Y}$ dan $\mathrm{X}$ dan $\varepsilon$ merupakan kemungkinan eror yang terjadi. Model kerja dari algoritma regresi dapat dilihat pada Gambar 5.

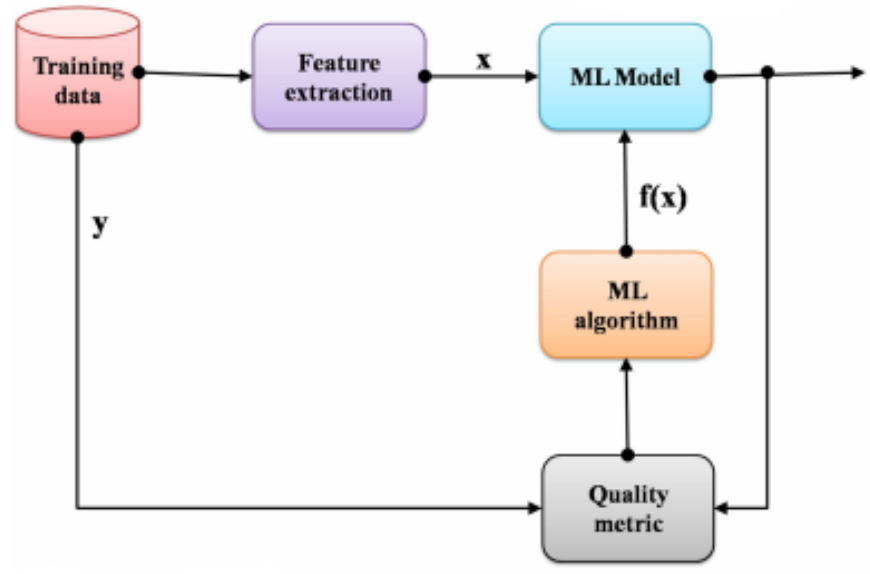

Gambar 5 Model kerja algoritma regresi [20]

2) Decision Tree: Merupakan algoritma yang termasuk berada dalam teknik supervised learning yang memproses data mulai dari pangkal (akar) lalu dilanjutkan dengan proses pengulangan sampai mencapai maksimum. Algoritma ini menganut aturan if-then. Decision tree terdiri dari 2 simpul, yaitu simpul hasil akhir dan simpul pilihan alternative [20]. Algoritma decision tree merupakan metode yang paling sering digunakan untuk klasifikasi dan prediksi. Decision tree memprediksi kelas atau data dengan menggunakan data training, dimana data training tersebut telah diatur sedemikian rupa dengan sebuah aturan (rule) untuk mendukung proses pengambilan keputusan [19][20]. Aturan dalam decision tree dapat ditampilkan dengan bahasa sehari-hari atau menggunakan query database seperti SQL. Selain prediksi dan klasifikasi, decision tree juga umum digunakan untuk eksplorasi data. Algoritma in isering digunakan untuk pengaplikasian di bidang diagnose penyakit. Sebagai contoh diagnose kanker, diagnose tumor, dan penyakit lainnya. Pada Gambar 6 ditampilkan contoh representasi grafik dari algoritma decision tree. 


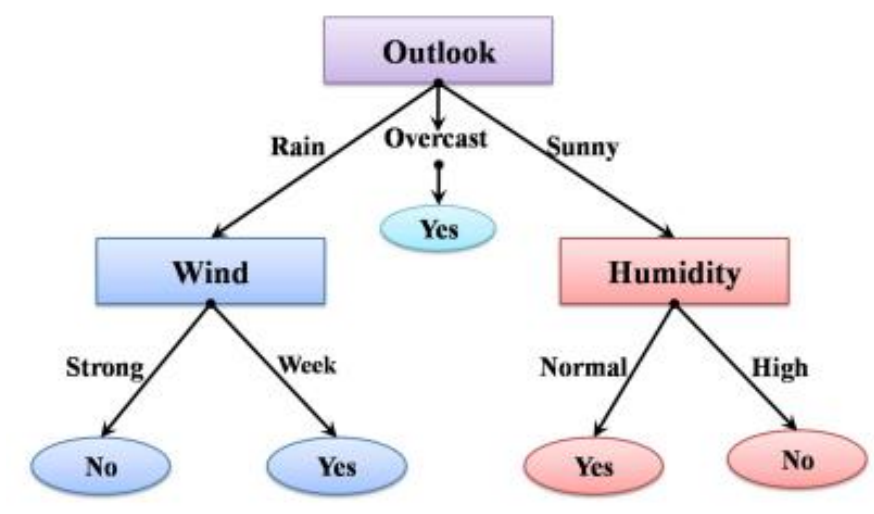

Gambar 6 Contoh Representasi Grafik Decision Tree [18][19]

3) Random Forest: Algoritma ini termasuk dalam algoritma supervised learning. Algoritma ini merupakan gabungan dari ratusan atau bahkan ribuan decision tree. Dimana tiap tree mewakili 1 klasifikasi. Algoritma ini muncul karena terkadang 1 decision tree dapat mengarah pada prediksi yang salah. Algoritma random forest cocok digunakan untuk dataset berukuran besar dan informasi yang heterogen. Algoritma ini bekerja dengan 2 tahap, antara lain tahap memproduksi klasifikasi data dan tahap memprediksi hasil. Algoritma akan mengklasifikasi data dari dataset inputan, lalu setelah data diklasifikasi, algoritma akan membantu untuk melakukan prediksi atau pengambilan keputusan dari data yang telah diklasifikasi sebelumnya [20]. Algoritma random forest umumnya digunakan untuk diagnosa penyakit dan rekomendasi. Sebagai contoh diagnosa kanker, rekomendasi pemilihan barang, dan lain sebagainya.

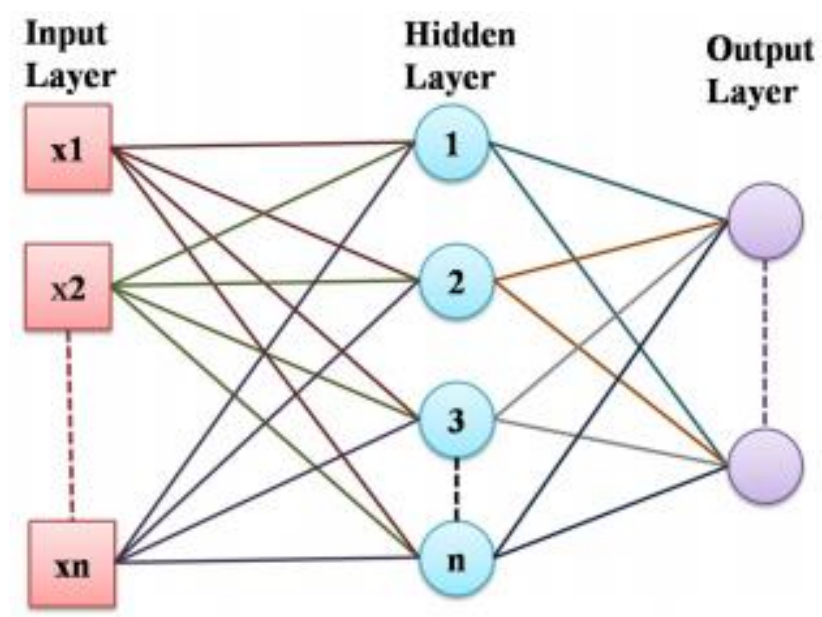

Gambar 7 Struktur Layer Algoritma ANN [18][19]

4) Artificial Neural Network: Algoritma ini termasuk dalam teknik supervised learning. Algoritma ini terinspirasi dari cara kerja neuron di otak manusia. Metode ini berhubungan dengan unit pemrosesan dalam jumlah besar yang mengolah informasi dan menghasilkan hasil yang akurat. Algoritma ANN beroperasi pada layer, dan layer-layer ini berhubungan dengan simpul dan tiap simpul berasosiasi dengan fungsi. Pada Gambar 7 dapat dilihat struktur layer dasar dari algoritma ANN. Tiap ANN berisi 3 layer antara lain layer input, satu atau lebih layer tersembunyi dan layer output. Dalam algoritma ANN ini, pengklasifikasian data yang kompleks dan non-linear dapat diatur dengan mudah [20].

5) Deep learning: Algoritma ini termasuk dalam teknik supervised learning. Deep learning merupakan sub kategori dari algoritma ANN. Algoritma ini merupakan algoritma data learning yang 
terdiri dari banyak layer antara layer input dan output. Algoritma ini tersusun dari modul non linear sederhana. Beberapa keuntungan dari algoritma deep learning adalah ektraksi fitur tingkat tinggi dari data, bekerja dengan atau tanpa label, dapat dilatih untuk memenuhi berbagai tujuan. Algoritma deep learning banyak digunakan untuk berbagai domain antara lain analisis jaringan social, intelijen bisnis, proses gambar medis, pengenalan suara dan pengenalan tulisan tangan [20][21].

6) Support Vector Machine: Merupakan algoritma machine learning yang masuk ke dalam kategori supervised learning. Algoritma ini berfungsi untuk klasifikasi dari sekumpulan data. Tingkat kompleksitas dari SVM tidak dipengaruhi oleh jumlah fitur yang terdapat di data training. Karena alasan tersebut, algoritma SVM sangat sesuai untuk tugas pembelajaran dimana jumalh fitur untuk pembelajaran tersebut banyak karena sesuai dengan jumlah data trainingnya yang juga banyak. Data training yang digunakan dalam algoritma SVM seringkali redundan. Maka diciptakanlah sebuah batas (boundary). Dalam algoritma ini terdapat support vector yang berfungsi untuk mengenali batasan [20].

7) Bayesian: Algoritma ini masuk ke dalam kategori supervised learning. Bayesian menggunakan pendekatan statistik. Algoritma ini mencari hubungan antar dataset dengan mempelajari kondisi independence menggunakan beberapa metode statistik, sebagai contoh Chi square test [11], [20]. Permasalahan yang umum diselesaikan dengan menggunakan algoritma ini antara lain lokalisasi, deteksi kesalahan, agregasi data, sinkronisasi, dan deteksi kejadian.

8) K-Nearest Neighbor: Menurut pemaparan dalam penelitian yang dilakukan Praveen Kumar [20], algoritma ini merupakan algoritma yang paling sederhana. Algoritma ini sering digunakan dalam regresi dan klasifikasi. Algoritma K-NN umumnya mengklasifikasikan berdasarkan jarak antar data training dan data tes. Algoritma K-NN menggunakan berbagai fungsi untuk mengukur jarak, antara lain Euclidean distance, Hamming distance, Canberra distance, Manhattan distance, Minkowski distance dan Chebycev distance. Tingkat kompleksitas dari algoritma ini tergantung dari ukuran dataset input.

9) K-means clustering: Merupakan algoritma machine learning yang masuk ke dalam kategori unsupervised learning. Algoritma ini bertujuan membagi data yang ada ke dalam satu atau lebih cluster. Pembagian data tersebut dilakukan agar data berkumpul dengan kelompok data lainnya yang memiliki karakteristik yang sama. Algoritma K-mean terdiri dari K yang berarti jumlah observasi dan $\mathrm{N}$ yang berarti jumlah cluster. Sehingga algoritma ini akan mendeteksi dataset menjadi beberapa observasi (K) yang kemudian dimasukkan ke dalam cluster (N) [20]. Algoritma ini sering digunakan untuk permasalahan pengenalan. Sebagai contoh pengenalan muka dan gambar, pengenalan video dan lain sebagainya.

10) Hierarchial clustering: algoritma ini mengelompokkan objek yang memiliki kemiripan ke dalam cluster, dimana cluster ini mempunyai ciri top-down dan bottom-up. Hirarki top-down dalam algoritma ini disebut juga divisive clustering. Pada divisive clustering, partisi tunggal berukuran besar akan dibagi sampai menjadi 1 cluster untuk tiap obeservasi. Sementara itu untuk pendekatan bottomup dalam algoritma ini disebut juga agglomerative clustering. Dalam pendekatan agglomerative clustering, tiap observasi ditetapkan untuk sebuah cluster yang sesuai dengan karakteristik observasi tersebut berdasarkan fungsi kepadatan. Dalam algoritma hierarchial clustering, tidak diperlukan informasi mengenai jumlah dari cluster sebelumnya [20]. Permasalahan yang umum diselesaikan menggunakan algoritma ini antara lain agregasi data, sinkronisasi dan panen energi.

11) Fuzzy c-means clustering: Algoritma ini masuk dalam kategori unsupervised learning dan umum digunakan untuk klasifikasi. Teknik dalam algoritma ini yaitu membuat cluster berdasarkan identifikasi yang dilakukan terhadap kemiripan dalam hal intensitas, jarak dan konektivitas. Algoritma ini akan melakukan iterasi terhadap cluster-cluster yang terbentuk sampai menemukan cluster yang optimal. Algoritma ini membutuhkan informasi mengenai jumlah dari cluster. Kompleksitas waktu dari algoritam FCM lebih tinggi dibandingkan dnegan pendekatan clustering lainnya dan sangat bergantung pada jumlah cluster, dimensi dan iterasi. Algoritma ini umum digunakan untuk 
menyelesaikan permasalahan terkait pengenalan pola, segmentasi gambar, dan business intelligence [20].

12) Singular value decomposition: Termasuk dalam algoritma unsupervised learning. Algoritma ini merupakan algoritma faktorisasi matriks yang digunakan untuk mengurangi dimensi. Dalam penelitian yang dilakukan oleh Klema, algoritma ini dapat menjamin akan low-rank representation dari data [20].

13) Principle component analysis: Merupakan algoritma unsupervised learning yang menganalisis multivariant ekstraksi fitur untuk mengurangi dimensi. Algoritma ini mengkombinasikan semua informasi dan menghilangkan informasi dengan prioritas data yang kecil untuk mengurangi dimensi. Output dari algoritma ini yaitu kombinasi linear dari variable yang diobservasi. Algoritma ini juga digunakan untuk mendekteksi anomali data seperti yang dilakukan di regresi [20]. Algoritma ini umumnya digunakan untuk mengatasi permasalahan seperti agregasi data, deteksi kesalahan dan lokalisasi.

14) Independent component analysis: Merupakan algoritma yang termasuk dalam kategori unsupervised learning. Algoritma ini memiliki cara kerja yang sama dengan mertode principle component analysis, hanya saja dalam algoritma ini dapat menghilangkan ketergantungan high order yang mana tidak bisa dilakukan di algoritma principle component analysis. Algoritma ini akan mencari dasra baru untuk representasi data dan mendekomposisi observasi multivariant menjadi subkomponen tambahan. Subkomponen dalam hal ini merupakan observasi non-Gaussian. Algoritma ini menganalisa data dari berbagai macam bidang aplikasi seperti konten website, gambar digital, business intelligence dan jaringan sosial [20].

\section{Teknik Machine learning}

Dalam machine learning, terdapat 4 teknik yang digunakan untuk melakukan prediksi untuk kepentingan pengambilan keputusan. Keempat teknik tersebut antara lain supervised learning, unsupervised learning, semi supervised learning dan reinforcement learning [20], [21]. Tiap teknik dalam machine learning akan dijelaskan sebagai berikut.

1) Supervised learning: Merupakan teknik untuk memprediksi hal di masa mendatang dengan menggunakan data histori yang digunakan sebagai variable. Ada 2 kategori dalam teknik supervised learning yaitu regresi dan klasifikasi. Regresi menggunakan variable kontinyu, sedangkan klasifikasi menggunakan variable klasifikasi. Regresi menggunakan data nilai real, numerik atau nilai pecahan untuk melakukan memprediksi. Contoh datanya misalnya data penjualan mobil dalam 5 tahun terakhir pada sebuah dealer mobil. Sementara itu klasifikasi membuat keputusan berdasarkan kategori atau label dari sebuah data [11], [19], [20][21].

2) Unsupervised learning: Merupakan teknik yang digunakan untuk melatih data yang tidak memiliki label. Tenik ini mencoba untuk mengekstrak atau membagi data berdasarkan struktur kemiripan data atau pola [11], [19], [20][21].

3) Semi Supervised learning: Teknik ini fokus pada data yang memiliki label dan tidak memiliki label atau dengan kata lain kombinasi. Kombinasi data tersebut digunakan untuk prediksi [11], [19], [20][21].

4) Reinforcement learning: Merupakan teknik yang digunakan untuk melatih data agar dapat mengambil keputusan berdasarkan kebutuhan bisnis dengan menggunakan algoritma berkelanjutan agar dapat mencapai hasil yang optimal. Hasil yang optimal disini memiliki arti risiko yang minimal tetapi kinerja yang dihasilkan maksimal [11], [19], [20][21].

Untuk melihat struktur hubungan antara teknik dalam machine learning dengan algoritma yang termasuk dalam kategori teknik machine learning, dapat dilihat pada Gambar 8. 


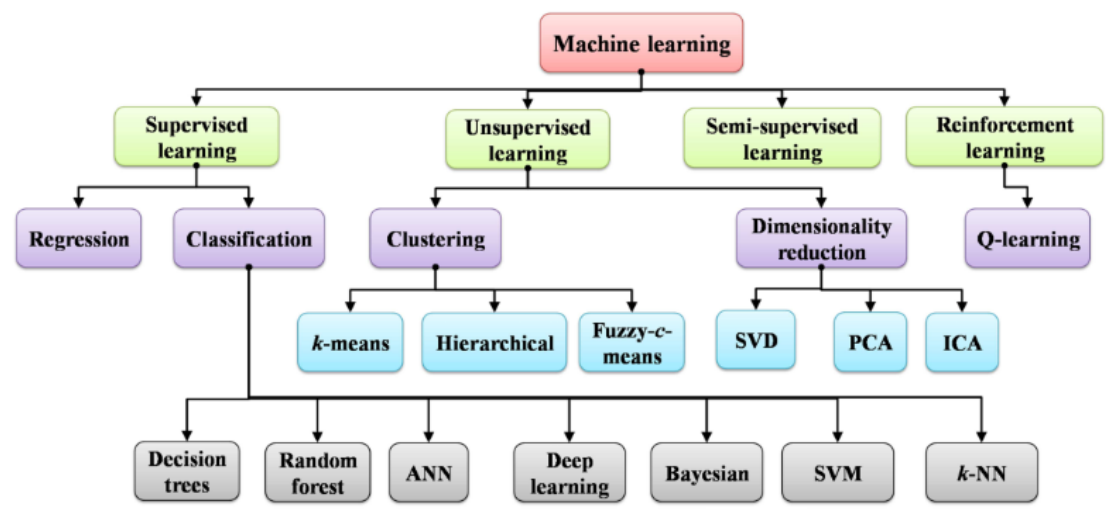

Gambar 8 Struktur Machine learning[20]

\section{PENELITIAN TERKAIT MACHINE LEARNING DAN IOT}

Penelitian terkait IoT yang melibatkan machine learning untuk proses pembelajarannya sudah banyak dilakukan. Wilayah pengaplikasiannya pun bervariasi, ada di bidang kesehatan. lingkungan, infrastruktur, cuaca dan lain sebagainya. Tujuan atau informasi yang ingin dicapai dengan mengkombinasikan antar machine learning dan IoT pun beragam. Pada bagian ini akan diangkat mengenai penelitian-penelitian yang telah dilakukan yang menggunakan kombinasi antara machine learning dan IoT.

Pada penelitian oleh Ahamed dan Farid [4], peneliti mengkombinasikan antara IoT dengan machine learning di bidang kesehatan. Dalam penelitian tersebut, kombinasi yang dilakukan tersebut memiliki tujuan untuk menghasilkan Personalized Healthcare (PH). PH merupakan pendekatan baru dalam bidang kesehatan beriorientasi pasien. Dengan adanya pendekatan baru ini, diharapkan dapat meningkatkan kinerja sistem kesehatan yang sudah ada. Fokus pendekatan PH ini adalah mengumpulkan data pasien yang diperoleh dari perangkat sensor, wearable sensor, perangkat bergerak, informasi yang tertera di situs, dan media sosial. Kemudian data pasien yang sudah terkumpul lewat perangkat tadi diolah menggunakan pendekatan machine learning sehingga dapat digunakan untuk meningkatkan teknik prediksi penyakit pasien, patient self-management, dan mendeteksi progress dari suatu penyakit. Peran dari machine learning dalam penelitian ini yaitu untuk model analisis. Model analisis ini terintegrasi dengan aplikasi layanan kesehatan dan sistem pendukung keputusan klinis. Model analisis ini menganalisa data yang terkumpul dari perangkat sensor, dan sumber lainnya untuk mengidentifikasi pola kebiasaan dan kondisi klinis dari pasien. Contoh pola makan, minum, tidur, kebiasaan sehari-hari, dan pola pencernaan. Berdasarkan pola-pola tersebut, aplikasi kesehatan dan sistem pendukung keputusan akan merekomendasikan gaya hidup yang lebih baik dan rencana perawatan untuk pasien. Dalam pemberian saran dan pengambilan keputusan, tentu melibatkan ahli terkait seperti dokter.

Selanjutnya penelitian yang dilakukan oleh Paul ,et.al [22] menggabungkan antara IoT dengan machine learning untuk smart building. Penelitian ini didasari oleh kepedulian terhadap penggunaan energi di sebuah bangunan. Kebutuhan akan energi terutama untuk bangunan sangat besar. Dalam penelitian ini diintegrasikan antara machine learning dan IoT untuk menghasilkan model prediksi yang dapat digunakan untuk peramalan suhu dari suatu ruangan di sebuah gedung. Hal tersebut mendukung program smart building yang bertujuan menghemat energi yang umumnya jika tidak menerapkan teknologi untuk smart building seperti IoT dan machine learning, akan menghabiskan energi yang besar. Selain itu, penelitian yang masih terkait dengan usaha penghematan energi dengan menerapkan IoT dan machine learning dalam suatu ruangan adalah penelitian yang dilakukan oleh AlHajri, et al. [5]. Penelitian tersebut menggunakan sensor untuk pelacakan dalam suatu ruangan. Hasil data dari sensor tersebut kemudian dianalisis menggunakan machine learning untuk menghasilkan keputusan apakah energi dibutuhkan atau tidak dalam ruangan tersebut, dimana hal tersebut dapat berdampak pada efisiensi dalam penggunaan energi. Selanjutnya penelitian terkait smart building yang menggunakan integrasi antara IoT dan machine learning juga dibahas dalam [23]. Dalam penelitian tersebut, energi yang dimaksud adalah pemanas, pendingin udara dan ventilasi. 
Selanjutnya penelitian yang melibatkan integrasi antara IoT dengan machine learning di bidang lingkungan yaitu penelitian yang dilakukan oleh Khan dan Khachane [24]. Dalam penelitian ini, fokus pada menjaga kebersihan dari lingkungan. Tumpukan sampah pada tempat pembuangan sampah membuat lingkungan menjadi kotor dan tidak layak. Hal tersebut dapat terjadi karena tidak adanya informasi kepada petugas kebersihan untuk mengangkut sampah dari tempat pembuangan tersebut atau bisa juga tidak adanya aksi yang terjadi untuk mencegah seseorang agar tetap membuang sampah di tempat pembuangan tersebut jika tempat pembuangan sampah sudah penuh. Sehingga diimplementasikanlah IoT dengan machine learning, dimana digunakan sensor untuk mendeteksi kepadatan dan ketinggian dari sampah yang kemudian data mengenai hal tersebut akan dianalisis menggunakan pendekatan machine learning sehingga akan menghasilkan keputusan langkah yang sebaiknya dilakukan untuk mengatasi sampah tersebut. Penelitian selanjutnya yang masih berhubungan dengan lingkungan dan manajemen sampah adalah penelitian yang dilakukan oleh Bakhshi dan Ahmed [6]. Penelitian tersebut mengintegrasikan IoT dengan machine learning untuk mengelola sampah pada suatu perkotaan demi mendukung dijalankannya konsep smart city pada kota tersebut. Penelitian selanjutnya yang mengintegrasikan antara IoT dengan machine learning adalah penelitian yang terkait dengan cuaca yang dilakukan oleh Onal, et al. [25]. Dalam penelitian ini dimanfaatkan perangkat sensor untuk mengumpulkan dataset yang tersedia di lingkungan yang kemudian dianalisis untuk melakukan peramalan cuaca.

\section{ISU DAN TANTANGAN MACHINE LEARNING DAN IOT}

Isu dan tantangan dalam penelitian yang melibatkan machine learning dan IoT tentu tidak terhindarkan. Berikut akan dibahas mengenai isu dan tantangan yang dihadapi dalam menerapkan kedua hal tersebut dalam beberapa bidang pengaplikasian penelitian. Isu dan tantangan terkait penerapan IoT yang menggunakan pendekatan machine learning untuk analisis data yang dikumpulkan dari perangkat IoT yang dihadapi dalam bidang kesehatan salah satunya terdapat pada penelitian yang dilakukan oleh Ahamed dan Farid [4]. Penelitian ini bergerak di bidang kesehatan. Isu dan tantangan yang terjadi di penelitian ini yaitu kebiasaan dan gaya hidup dari seorang pasien merupakan hal yang sangat sensitif dan susah untuk ditemukan polanya karena seringkali berubah. Selain itu saat pengumpulan data, bisa terjadi bahwa data yang terkumpul tidak valid sehingga mengganggu hasil dari proses pengambilan keputusan. Selain itu dataset yang dimiliki bisa jadi merupakan data lama, sehingga jika digunakan untuk menghasilkan sebuah saran medis untuk pasien menjadi tidak valid dengan kondisi pasien saat ini.

Selain itu, isu dan tantangan di bidang IoT dan machine learning bukan hanya di bidang kesehatan, melainkan di semua bidang pengaplikasian yang menerapkan IoT dan machine learning yaitu bagaimana agar aman dan yakin tidak ada data yang hilang saat proses transmisi data dari perangkat ke tempat penyimpanan data. Selain itu masalah privasi data yang terkumpul lewat sensor juga menjadi isu dan tantangan bagi penelitian selanjutnya. Data pribadi individu merupakan hal yang sensitif, sehingga bagaimana menjaga agar data tersebut tidak bocor dan diterima oleh pihak yang tidak berkepentingan untuk menghindari penyalahgunaan data. Tantangan dan isu lainnya terkait penerapan kombinasi antara IoT dengan machine learning yaitu tingkat kepercayaan terhadap data. Bagaimana agar pengguna yakin bahwa data yang digunakan adalah data yang valid dan aktual. Protokol dari IoT yang beragam juga merupakan isu dan tantangan tersendiri dalam sebuah penelitian yang melibatkan IoT dan machine learning [5], [22], [26], [27][28].

\section{KESIMPULAN}

Internet of things mengubah cara pandang, cara bekerja dan kebutuhan hidup. Proses belajar dari sekumpulan data secara otomatis membuat hidup menjadi lebih mudah dan sederhana. IoT akan menghasilkan data dalam jumlah yang besar, sementara machine learning membutuhkan data dalam jumlah besar untuk proses belajar. Melaui kombinasi antara kedua hal tersebut, akan dapat mencapai banyak tujuan dan membuat hidup manusia lebih mudah dan nyaman. Kemudahan dan kenyamanan hidup yang bisa didapatkan melalui IoT dan machine learning dibarengi pula dengan sisi negatifnya. Ketika semuanya terhubung, maka privasi data dan kebocoran data menjadi masalah yang akan dihadapi. Tetapi dari semua itu, di masa yang akan depan integrasi antara IoT dengan machine learning akan menguasai dunia. 


\section{REFERENSI}

[1] J. M. Khurpade, D. Rao, and P. D. Sanghavi, "A Survey on IOT and 5G Network," 2018 Int. Conf. Smart City Emerg. Technol. ICSCET 2018, pp. 1-3, 2018.

[2] A. Al-Fuqaha, M. Guizani, M. Mohammadi, M. Aledhari, and M. Ayyash, "Internet of Things: A Survey on Enabling Technologies, Protocols, and Applications," IEEE Commun. Surv. Tutorials, vol. 17, no. 4, pp. 2347-2376, 2015.

[3] R. Khan, S. U. Khan, R. Zaheer, and S. Khan, "Future internet: The internet of things architecture, possible applications and key challenges," Proc. - 10th Int. Conf. Front. Inf. Technol. FIT 2012, pp. 257-260, 2012.

[4] F. Ahamed and F. Farid, "Applying Internet of Things and Machine- learning for Personalized Healthcare: Issues and Challenges," 2018 Int. Conf. Mach. Learn. Data Eng., pp. 19-21, 2019.

[5] M. I. Alhajri, N. T. Ali, and R. M. Shubair, "Classification of Indoor Environments for IoT Applications: A Machine learning Approach," IEEE Antennas Wirel. Propag. Lett., vol. 17, no. 12, pp. 2164-2168, 2018.

[6] T. Bakhsi and M. Ahmed, "IoT Enabled Smart City Waste Management using Machine learning Analytics," vol. 7, pp. 3-8, 2018.

[7] M. Wu, T. J. Lu, F. Y. Ling, J. Sun, and H. Y. Du, "Research on the architecture of Internet of Things," ICACTE 2010 - 2010 3rd Int. Conf. Adv. Comput. Theory Eng. Proc., vol. 5, pp. 484487, 2010.

[8] Z. Yang, Y. Yue, Y. Yang, Y. Peng, X. Wang, and W. Liu, "Study and application on the architecture and key technologies for IOT," 2011 Int. Conf. Multimed. Technol. ICMT 2011, pp. 747-751, 2011.

[9] L. Atzori, A. Iera, and G. Morabito, "The Internet of Things: A survey," Comput. Networks, vol. 54, no. 15 , pp. 2787-2805, 2010.

[10] M. A. Chaqfeh and N. Mohamed, "Challenges in middleware solutions for the internet of things," Proc. 2012 Int. Conf. Collab. Technol. Syst. CTS 2012, pp. 21-26, 2012.

[11] J. Xie, F. R. Yu, T. Huang, R. Xie, J. Liu, and Y. Liu, "A Survey of Machine learning Techniques Applied to Software Defined Networking (SDN): Research Issues and Challenges," IEEE Commun. Surv. Tutorials, vol. PP, no. c, p. 1, 2018.

[12] N. Koshizuka and K. Sakamura, "Ubiquitous ID: Standards for ubiquitous computing and the internet of things," IEEE Pervasive Comput., vol. 9, no. 4, pp. 98-101, 2010.

[13] R. Want, "An introduction to RFID technology," IEEE Pervasive Comput., vol. 5, no. 1, pp. 2533, 2006.

[14] R. Want, "Smartphones: Near Field Communication,” pp. 4-7, 2011.

[15] F. P. Erina Ferro, "Bluetooth and Wi-Fi Wireless Protocols :," IEEE Wirel. Commun. Mag., pp. $1-24,2004$.

[16] P. McDermott-Wells, "What Is Bluetooth?," IEEE Potentials, 23(5), 33-35., vol. 48, no. 9, pp. $1-16,2005$.

[17] G. V. Crosby and F. Vafa, "Wireless sensor networks and LTE-A network convergence," Proc. Conf. Local Comput. Networks, LCN, no. August, pp. 731-734, 2013.

[18] M. Gigli and S. Koo, "Internet of Things: Services and Applications Categorization," no. January 2011, 2016.

[19] S. Jaspers, E. De Troyer, and M. Aerts, "Machine learning techniques for the automation of literature reviews and systematic reviews in EFSA," EFSA Support. Publ., vol. 15, no. 6, 2018.

[20] D. Praveen Kumar, T. Amgoth, and C. S. R. Annavarapu, "Machine learning algorithms for wireless sensor networks: A survey," Inf. Fusion, vol. 49, pp. 1-25, 2019.

[21] U. S. Shanthamallu, A. Spanias, C. Tepedelenlioglu, and M. Stanley, "A brief survey of machine learning methods and their sensor and IoT applications," 2017 8th Int. Conf. Information, Intell. Syst. Appl. IISA 2017, vol. 2018-January, pp. 1-8, 2018.

[22] D. Paul, T. Chakraborty, S. K. Datta, and D. Paul, "IoT and Machine learning Based Prediction of Smart Building Indoor Temperature," 2018 4th Int. Conf. Comput. Inf. Sci. Revolutionising Digit. Landsc. Sustain. Smart Soc. ICCOINS 2018 - Proc., pp. 1-6, 2018. 
[23] A. Javed, H. Larijani, and A. Wixted, "Improving Energy Consumption of a Commercial Building with IoT and Machine learning," IT Prof., vol. 20, no. 5, pp. 30-38, 2018.

[24] A. Khan and A. Khachane, "Survey on IOT in Waste Management System," 2018 2nd Int. Conf. I-SMAC (IoT Soc. Mobile, Anal. Cloud) (I-SMAC)I-SMAC (IoT Soc. Mobile, Anal. Cloud) (ISMAC), 2018 2nd Int. Conf., pp. 27-29, 2019.

[25] A. C. Onal, O. Berat Sezer, M. Ozbayoglu, and E. Dogdu, "Weather data analysis and sensor fault detection using an extended IoT framework with semantics, big data, and machine learning," Proc. - 2017 IEEE Int. Conf. Big Data, Big Data 2017, vol. 2018-January, pp. 20372046, 2018.

[26] C. M. Chung, C. C. Chen, W. P. Shih, T. E. Lin, R. J. Yeh, and I. Wang, "Automated machine learning for Internet of Things," 2017 IEEE Int. Conf. Consum. Electron. - Taiwan, ICCE-TW 2017, pp. 295-296, 2017.

[27] R. R. Reddy, C. Mamatha, and R. G. Reddy, "A Review on Machine learning Trends, Application and Challenges in Internet of Things," 2018 Int. Conf. Adv. Comput. Commun. Informatics, ICACCI 2018, pp. 2389-2397, 2018.

[28] M. Mamdouh, M. A. I. Elrukhsi, and A. Khattab, "Securing the Internet of Things and Wireless Sensor Networks via Machine learning: A Survey," 2018 Int. Conf. Comput. Appl. ICCA 2018, no. Section II, pp. 215-218, 2018. 